\title{
Optic Cup
}

National Cancer Institute

\section{Source}

National Cancer Institute. Optic Cup. NCI Thesaurus. Code C34233.

A double walled invag ination of the optical vesicles in the early embryo, which forms the neural retina from its inner wall, the retinal pigment epithelium from its outer wall, and the ciliary body and iris from its rim. 